\title{
Correlates of Controlled Hypertension in Indigent, Inner-City Hypertensive Patients
}

\author{
Jasjit S. Ahluwalia, MD, MPH, MS, Sally E. McNagny, MD, MPH, \\ Kimberly J. Rask, MD, PhD
}

\begin{abstract}
OBJECTIVE: To identify correlates of controlled hypertension in a largely minority population of treated hypertensive patients.
\end{abstract}

DESIGN: Case-control study.

SETTING: Urban, public hospital.

PATIENTS: A consecutive sample of patients who were aware of their diagnosis of hypertension for at least 1 month and had previously filled an antihypertensive prescription. Control patients had a systolic blood pressure (SBP) $\leq 140 \mathrm{~mm}$ $\mathrm{Hg}$ and diastolic blood pressure (DBP) $\leq 90 \mathrm{~mm} \mathrm{Hg}$, and case patients had a SBP $\geq 180 \mathrm{~mm} \mathrm{Hg}$ or DBP $\geq 110 \mathrm{~mm} \mathrm{Hg}$.

MEASUREMENTS AND MAIN RESULTS: Control subjects had a mean blood pressure (BP) of $130 / 80 \mathrm{~mm} \mathrm{Hg}$ and case subjects had a mean BP of 193/106 mm Hg. Baseline demographic characteristics between the 88 case and the 133 control subjects were not significantly different. In a logistic regression model, after adjusting for age, gender, race, education, owning a telephone, and family income, controlled hypertension was associated with having a regular source of care (odds ratio [OR] 7.93; 95\% confidence interval [CI] 3.86, 16.29), having been to a doctor in the previous 6 months (OR 4.81; 1.14, 20.31), reporting that cost was not a deterrent to buying their antihypertensive medication (OR $3.63 ; 1.59,8.28$ ), and having insurance (OR 2.15; 1.02, 4.52). Being compliant with antihypertensive medication regimens was of borderline significance (OR 1.96; 0.99, 3.88). A secondary analysis found that patients with Medicaid coverage were significantly less likely than the uninsured to report cost as a barrier to purchasing antihypertensive medications and seeing a physician.

CONCLUSIONS: The absence of out-of-pocket expenditures under Medicaid for medications and physician care may contribute significantly to BP control. Improved access to a regular source of care and increased sensitivity to medication costs for all patients may lead to improved BP control in an indigent, inner-city population.

KEY WORDS: inner-city patients; hypertension; access to care; regular source of care.

J GEN INTERN MED 1997;12:7-14.

Received from the Department of Medicine, Emory University School of Medicine (JSA, SEM, KJR) and the Department of Health Policy and Management (JSA, KJR) and Department of Epidemiology (SEM), Rollins School of Public Health, Atlanta, Ga.

Presented at the Society of General Internal Medicine 18th annual meeting, San Diego, Calif., May 4-6, 1995.

Supported by an unrestricted grant from Marion Merrell Dow, Inc.

Address correspondence and reprint requests to Dr. Ahluwalia: Emory University School of Medicine, 69 Butler St., Atlanta, GA 30303.
$\mathbf{H}$ ypertension, which affects 50 million Americans, remains the most common medically treatable chronic disease. ${ }^{1}$ In 1991, it was the leading reason for an office visit, accounting for 23 million visits. ${ }^{2}$ Great strides have been made since the 1940s when President Franklin D. Roosevelt's stage 4 (very severe) hypertension went untreated. ${ }^{3}$ In the past 20 years, the prevalence of hypertensive patients aware of their diagnosis has doubled, the prevalence of treated hypertensive patients has doubled, and the prevalence of controlled hypertensive patients has tripled. ${ }^{4}$ The overall increase in blood pressure (BP) control has largely been driven by increased awareness and initiation of treatment for previously undiagnosed hypertension. However, significant work remains in controlling BP in persons with known hypertension. Recent work has found that hypertension had been previously diagnosed in more than $90 \%$ of inner-city, minority patients with hypertensive emergencies. ${ }^{5}$ Despite the availability of five classes of effective antihypertensive agents, the level of BP control in known hypertensive patients currently under treatment is poor. ${ }^{6}$ Using the revised definition of hypertension, a systolic blood pressure (SBP) $\geq 140 \mathrm{~mm}$ $\mathrm{Hg}$ or a diastolic blood pressure (DBP) $\geq 90 \mathrm{~mm} \mathrm{Hg}$ on a single occasion, national data from 1988 through 1991 show that among hypertensive patients, 69\% are aware of their diagnosis, 53\% are being treated, and $24 \%$ have controlled BP. ${ }^{1,4,7}$ Of patients currently receiving antihypertensive treatment, only $45 \%$ have controlled hypertension (SBP $<140 \mathrm{~mm} \mathrm{Hg}$ and $\mathrm{DBP}<90 \mathrm{~mm} \mathrm{Hg}$ ).

Uncontrolled hypertension is even more prevalent in minority and disadvantaged populations. ${ }^{8-10}$ Seventy-four percent of African Americans who are hypertensive are aware of their diagnosis, $57 \%$ are treated, and only $25 \%$ are controlled. ${ }^{7}$ Severe hypertension is five to seven times more prevalent in certain minority groups. ${ }^{11}$ In addition to being more prevalent and more severe, hypertension in minority populations has more serious consequences. ${ }^{12,13}$ Compared with U.S. whites, African Americans have an increased risk of cardiovascular mortality, end-stage renal disease, and stroke. ${ }^{11,12,14}$ One of the national health objectives for the year 2000 is to increase the rate of patients with controlled BP to at least 50\%. ${ }^{15}$

A previously described model of access to care, the Anderson-Aday model, describes three types of population characteristics that influence the use of medical services. ${ }^{16}$ These are predisposing characteristics, such as age, gender, ethnicity, and knowledge; enabling characteristics, such as income, insurance, and usual source of care; and need characteristics, such as health status and comorbidity. Several of these characteristics have been 
studied in relation to BP control. Some studies suggest that interventions which improve patient knowledge about hypertension may lead to controlled BP in the short term. ${ }^{17-19}$ Severe uncontrolled hypertension was more common among patients who had no primary care physician and among those who were noncompliant with their antihypertensive medication regimens. ${ }^{20}$ Previous work with hypertensive adults in a state Medicaid program ${ }^{21}$ and in a Department of Veterans Affairs population ${ }^{22}$ found that those terminated from their insurance program were found to have BP significantly worse than their baseline pressure prior to termination of these benefits. Similar findings were discovered in the RAND Health Insurance Experiment, a large multicenter randomized trial. ${ }^{23}$ Data from national surveys support the association of a regular source of care and health insurance with hypertension screening, follow-up care for hypertension, and the use of pharmacologic treatment. ${ }^{24,25}$ However, these studies do not provide data on the relationship between source of care or insurance status (Medicaid vs private insurance) and the level of BP control in patients in an outpatient setting. In addition, even though data indicate that the cost of antihypertensive medications and physician visits is a problem, ${ }^{13,23,26-28}$ this cost has not been linked to the level of BP control. With regard to insurance, many studies have suggested a stepwise differential in access to care, receipt of medical care, and health-related outcomes, with private insurance being better than Medicaid, which in turn is better than no insurance. ${ }^{25,29-32}$

We conducted a case-control study to examine the effects of predisposing, enabling, and need characteristics of patients on BP control. Our patients were known to be hypertensive and were being treated in an inner-city ambulatory clinic for a range of medical reasons. First, we tested the hypothesis that the patients whose BP was controlled would be more likely to be knowledgeable about hypertension, to have a regular source of care, to be compliant with their antihypertensive medication regimens, to have public or private health insurance, and to state that the cost of antihypertensive medications and physician visits does not serve as a deterrent. Second, because patients are aware that Medicaid and private insurance are accepted equally at our institution, we hypothesized that patients with Medicaid would have levels of BP control similar to those with private insurance. Finally, we examined how patients' beliefs about the cost of antihypertensive medications and physician visits were related to their insurance coverage.

\section{METHODS}

\section{Setting and Subjects}

The study was conducted over a period of 12 weeks in 1994 at an urban hospital serving low-income, predominantly African-American residents of a two-county area. The clinic is open to ambulatory patients with nonsurgical medi- cal complaints ranging from medication refills, to acute and chronic medical conditions. All patients who came to the walk-in clinic between the hours of $8 \mathrm{AM}$ and 5 PM on weekdays were screened for eligibility to participate in a casecontrol study. Hypertensive patients with a BP of greater than $240 / 140 \mathrm{~mm} \mathrm{Hg}$ were referred immediately to the emergency department and were not eligible for the study.

To be eligible for the study, all patients had to be aware of their diagnosis of hypertension for at least 1 month and to have filled an antihypertensive prescription, as documented on their hospital computerized profile. Prisoners and mentally incapacitated, nursing home, and non-English-speaking patients were excluded.

\section{Data Collection}

Data were collected by a single trained research assistant who was a physician. The study was approved by the Emory University Human Investigations Committee, and written informed consent was obtained from all patients. Owing to the prevalence of low literacy among our patients, ${ }^{33}$ the consent form was read aloud, and the research assistant administered the survey instrument and circled all responses. The survey instrument was pilot tested, and questions were revised to increase comprehension.

\section{Measurements}

One research assistant performed all the manual BP measurements after the patient was seated for 5 minutes. Measurements were completed using one of four cuff sizes (pediatric, regular adult, large, or thigh) chosen according to the circumference of the participant's arm, as indicated by the manufacturer's guidelines. Instrument bias was minimized by utilizing a standard mercury sphygmomanometer (W.A. Baum Co., Inc.) throughout the study. The operational definition of SBP was the first sound heard, with care not to measure after the auscultatory gap. ${ }^{34}$ The operational definition of DBP was when sound ceased to be heard, not when sounds became muffled. To maximize precision, the cuff was deflated $2 \mathrm{~mm} \mathrm{Hg} / \mathrm{s}$ on all patients. Uncontrolled hypertension was defined using the Joint National Committee V classification for severe hypertension as $\mathrm{SBP} \geq 180$ or $\mathrm{DBP} \geq 110 \mathrm{~mm} \mathrm{Hg}$ (at least stage 3 hypertension). Controlled hypertension was defined as $\mathrm{SBP} \leq 140$ and $\mathrm{DBP} \leq 90 \mathrm{~mm} \mathrm{Hg}$. The manual $\mathrm{BP}$ reading determined final eligibility for the study. ${ }^{35} \mathrm{~Pa}-$ tients with stage 1 or stage 2 hypertension (SBP $=141-$ $179 \mathrm{~mm} \mathrm{Hg}$ and/or DBP = 91-109 $\mathrm{mm} \mathrm{Hg}$ ) were excluded from the study so as to maximize the contrast between our two study groups, patients with controlled hypertension and patients with severe uncontrolled hypertension.

Age, gender, ethnicity, mode of transportation, home ownership, educational level, household income, marital status, use of health services, and employment were obtained during the interview by patient self-report. Insurance status was obtained from hospital administrative 
records. Having a regular source of care was defined by a patient's response to the following question: "Do you have a clinic or doctor that you go to on a regular basis?" If they responded yes, and the source was the hospital continuity clinic, a private doctor's office, an HMO, or a continuity clinic at the county health center, then they were considered to have a regular source of care. If patients answered no, or stated that they went to the emergency department or walk-in clinic on a regular basis, they were considered not to have a regular source of care. Questions about smoking and tobacco use were taken from the 1988 National Health Interview Survey (NHIS). ${ }^{36}$

To assess the general health status of survey participants, we used a self-rated global assessment of health status from the Short Form-36 Medical Outcomes Study Health Survey. ${ }^{37}$ The question asked is: "In general would you say your health is: excellent, very good, good, fair, or poor?" Patients who reported consuming more than 12 alcoholic beverages in their life were asked the four CAGE questions, a screening instrument for alcohol dependency ${ }^{38}$ : Have you ever felt the need to cut down on your drinking? Have you ever felt annoyed by criticism of your drinking? Have you ever had guilty feelings about your drinking? Have you ever taken a morning eye-opener? Answering yes to two or more of these questions has been found to predict alcohol dependency with a sensitivity of $74 \%$ and a specificity of $91 \% .^{39}$ Patients were asked if they had used cocaine, crack, heroin, or marijuana in the past year. We designed and pilot tested four questions to measure selfreported prevalence of diabetes, myocardial infarction, stroke, and congestive heart failure, as follows: "Have you ever been told you have diabetes (high sugar, sugar in the blood)? Have you ever been told you have had a heart attack? Have you ever been told you have had a stroke? Have you ever been told you have had congestive heart failure (CHF, fluid or water in the lungs)?"

A previously validated four-question scale, the Morisky scale, was used to assess self-reported compliance with medications. ${ }^{40,41}$ The Morisky scale questions are: "Do you ever forget to take your high blood pressure pills? Are you ever careless in taking your pills? Do you ever miss taking your pills when you are feeling better? Do you ever miss taking any of your pills when you are feeling sick?" A patient who answered yes to one or more of these four questions was considered to be noncompliant. The number of hypertension medications being taken by patients was assessed by utilizing the hospital's computerized pharmacy records, by reviewing the medication bottles the patients had with them, and by patient recall.

Questions related to knowledge about hypertension included questions from the 1985 NHIS, ${ }^{36}$ an additional multiple-choice question, and three open-ended questions. The three questions from the NHIS were: "Which one of the following things makes blood pressure worse? Cholesterol, Salt, Sugar, or Don't Know"; "The last time your blood pressure was checked, was your blood pressure...? High, Low, Normal, or Don't Know"; and "The last time your blood pressure was checked, were you told what your blood pressure was in numbers? Yes, No, Don't Know." The additional multiple-choice question was: "Which group gets more high blood pressure? White Americans, African Americans, Both groups are at the same risk, Don't Know." The three open-ended questions were: "Please name the blood pressure pills that you are on?" "Besides taking high blood pressure medicine, please tell me other things you can do, or could do, to help control your blood pressure?" and "Can you tell me some of the medical problems that high blood pressure can cause?"

\section{Statistical Analysis}

Data from the questionnaires were double-entered into EpiInfo Version 5.01.42 Bivariate associations were tested with use of $\chi^{2}$ statistic for categorical data and Student's $t$ test for age. The Fisher Exact Test was used for tables with fewer than five subjects in any cell. Odds ratios (ORs) were used to approximate relative risks. Multivariate logistic regression models were used to calculate adjusted ORs. ${ }^{43}$ In the regression models, the outcome variable was controlled hypertension versus uncontrolled hypertension, and the independent variables were coded as age (continuous in years), gender (male vs female), race (African American vs other), educational level (more than vs less than a high school education), insurance status (insured vs uninsured), source of care (presence vs absence of a regular source of care), duration of hypertension ( $\geq 6$ vs $<6$ months), employment status (full- or part-time employed vs unemployed or retired), compliance (compliant vs noncompliant by the Morisky scale), alcoholism ( $\geq 2$ positive questions vs $<2$ positive questions on the CAGE), illicit drug use ( $\geq 1$ drug or none), antihypertensive medications ( 1 medication vs $\geq 2$ ), and comorbidity (presence vs absence of one of the following four by self-report: diabetes mellitus, stroke, congestive heart failure, or heart attack). For the knowledge questions: the diet question was coded as correct (salt) versus incorrect (other answers); knowledge of previous BP was coded as knowing it was high, low, or normal versus don't know; being told BP in numbers at the last check was coded yes versus no or don't know; and knowledge about ethnicity and hypertension was coded as correct (African American) versus incorrect (other groups). For the three open-ended questions, a correct response was the ability to correctly name, or phonetically pronounce, at least one of their antihypertensive medications versus no medication correctly named. The second open-ended question was to correctly identify any of the following correct responses as nonpharmacologic maneuvers to lower one's BP: avoid salt, lose weight, decrease alcohol consumption, exercise, and decrease pork consumption. Finally, the third openended question was to identify at least one of the following medical sequelae of hypertension: heart disease, stroke, arterial disease, eye disease, and kidney disease. 


\section{RESULTS}

After identifying 222 eligible patients, we enrolled 133 patients with controlled hypertension ( $\leq 140 / 90 \mathrm{~mm} \mathrm{Hg}$ ) and 88 patients with uncontrolled hypertension (stage 3 or stage 4 hypertension) consecutively as they came to the clinic over a period of 12 weeks. There was one patient refusal. None of the 221 patients enrolled was hospitalized or sent to the emergency department on the day of the survey. The two groups of patients were similar with regard to age, ethnicity, gender, education, employment, marital status, self-reported comorbidity, alcoholism, use of illicit drugs, number of antihypertensive medications, self-reported health status, and knowledge about hypertension (Table 1). Two thirds of study participants had not finished high school, 24\% were employed, and a significant majority reported being in fair or poor health. Even though our inclusion criteria required that all of our patients had knowledge of their diagnosis of hypertension for at least 1 month, $94 \%$ of patients were aware of being hypertensive for more than 6 months. Other knowledge levels were high; more than $95 \%$ of patients knew if their most recent $\mathrm{BP}$ reading was high, low, or normal. In addition, two thirds of patients could name at least one nonpharmacologic method to lower BP and could name one medical consequence of hypertension. However, only $60 \%$ stated that at their last BP check they were told their BP in numbers, and less than a third could correctly name one of their antihypertensive medications. Patients differed in their mean BP: patients with uncontrolled BP had a mean SBP of $192 \mathrm{~mm} \mathrm{Hg}$ (range 162-228 mm Hg), and patients with controlled BP had a mean SBP of $130 \mathrm{~mm} \mathrm{Hg}$ (103-140 $\mathrm{mm} \mathrm{Hg}$. The mean DBP was $106 \mathrm{~mm} \mathrm{Hg}$ (72-138 mm Hg) compared with $80 \mathrm{~mm} \mathrm{Hg}$ (60-90 mm Hg), respectively.

When we compared patients with controlled and those with uncontrolled hypertension, the following were found to be significantly correlated with controlled BP: having a regular source of care, $84 \%$ versus 39\% (OR 8.33; 95\% confidence interval [CI] 4.35, 16.67); having been to a doctor in the last 6 months, 97\% versus $83 \%$ (OR 6.33; 1.94, 24.91); cost not being a deterrent in purchasing antihypertensive medications, $89 \%$ versus $67 \%$ (OR 3.87; 1.82, 8.31); cost not being a deterrent in seeing a physician, $83 \%$ versus $67 \%$ (OR 2.35 ; $1.19,4.67$ ); having medical insurance, $71 \%$ versus $49 \%$ (OR 2.62; 1.43 , 4.81); having one's own telephone, $92 \%$ versus $83 \%$ (OR $2.53 ; 1.00,6.49$ ); and being compliant with antihypertensive medication regimens, $67 \%$ versus $47 \%$ (OR 2.33; $1.28,4.17)$. Having a family income above poverty level was of borderline significance, $44 \%$ versus $31 \%$ (OR 1.75; $0.95,3.23)$. Further breakdown of insurance coverage showed that of those with insurance, 44 patients had

Table 1. Characteristics of Study Patients

\begin{tabular}{|c|c|c|c|}
\hline Characteristic & Controlled $(n=133)$ & Uncontrolled $(n=88)$ & $p$ Value \\
\hline Mean age, years & 57 & 56 & .54 \\
\hline Female, \% & 73 & 72 & .83 \\
\hline Education $\geq$ high school graduate, $\%$ & 32 & 30 & .66 \\
\hline \multicolumn{4}{|l|}{ Employment, \% } \\
\hline Married, \% & 20 & 18 & .80 \\
\hline At least one self-reported comorbidity, $\%$ & 35 & 41 & .40 \\
\hline Diabetes mellitus & 18 & 24 & .29 \\
\hline Myocardial infarction & 14 & 14 & .98 \\
\hline Cerebrovascular accident & 10 & 10 & .91 \\
\hline Fair or poor health status, $\%$ & 67 & 67 & .89 \\
\hline \multicolumn{4}{|l|}{ Knowledge, \% } \\
\hline Of previous BP being high, low, or normal & 96 & 97 & .60 \\
\hline Association of salt with hypertension & 83 & 85 & .72 \\
\hline At last check, told BP in numbers & 60 & 58 & .74 \\
\hline That African Americans affected by hypertension more than whites & 80 & 81 & .86 \\
\hline Correctly name one of their antihypertensive BP medications & 31 & 28 & .61 \\
\hline Able to name $\geq 1$ nonpharmacologic method to lower BP & 74 & 65 & .12 \\
\hline Able to name $\geq 1$ medical consequence of hypertension & 89 & 86 & .48 \\
\hline
\end{tabular}

*BP indicates blood pressure. 
Medicaid and 93 had other forms of insurance. Of these 93 patients, 79 had Medicare, and the remaining 14 had other forms of private insurance. Using the uninsured as the referent group, patients with Medicaid coverage were more likely to have controlled BP, $77 \%$ versus $46 \%$ (OR $4.0 ; 1.64,10.00)$, as were patients with other forms of insurance, $65 \%$ versus $46 \%$ (OR $2.17 ; 1.12,4.17$ ). None of our six measures for hypertension-related knowledge was associated with controlled hypertension.

Variables found to be significant in the bivariate analyses were candidates for entry into a multivariate logistic regression model (Table 2). Because of the high correlation between questions about cost of medications and cost of physician visits, the former variable, with a higher OR in the bivariate analysis, was entered into the multivariate logistic regression. Because of the potential colinearity between cost, insurance, and compliance, we first estimated the model without the cost variable. When cost was added to the model, there were minimal changes in the OR. After adjusting for age, gender, race, owning a telephone, and family income, the following variables were associated with controlled hypertension: having a regular source of care (OR 7.93; 95\% CI 3.86, 16.29), having been to a doctor in the previous 6 months (OR 4.81; 1.14, 20.31), cost not a deterrent in purchasing antihypertensive medication (OR 3.63; 1.59, 8.28), and health insurance coverage (OR 2.15; 1.02, 4.52). Being compliant with antihypertensive medication regimens was of borderline statistical significance (OR 1.96; 0.99, 3.88).

We conducted a secondary analysis to assess the relationship between insurance status and two financial barriers to care-cost of medications and cost of physician visits. Using uninsured patients as the referent group, patients with Medicaid coverage were significantly more likely than the uninsured to report that cost was not a barrier to purchasing antihypertensive medications, 93\% versus 69\% (OR 6.25; 95\% CI 1.61, 25.00), as were patients with other forms of insurance, $84 \%$ versus $69 \%$ (OR $2.38 ; 1.09,5.26)$. Medicaid patients were also more likely to report that cost was not a barrier to making physician visits, 93\% versus 57\% (OR 10.00; 2.78, 50.00), as was true for patients with other forms of insurance, $86 \%$ versus $57 \%$ (OR $4.76 ; 2.13,11.11$ ). For both medications and physician visits, the effect was most marked for Medicaid recipients.

\section{DISCUSSION}

This study supports our hypothesis that having a regular source of care, seeing a doctor regularly, absence of cost barriers, and insurance coverage are associated with controlled BP in an inner-city, outpatient population of patients with known hypertension. By studying patients with controlled hypertension, we were able to find variables associated with successful control of BP in an inner-city outpatient population. These findings are consistent with those of a previous study conducted in a similar demographic population of patients with hypertensive emergency, some of whom were hospitalized. ${ }^{20}$ Our study builds on this previous work and is the first to show that the absence of cost barriers to purchasing antihypertensive medications and making physician visits, and having recently been to a physician, were associated with controlled BP. Higher household income was not independently associated with controlled hypertension.

The interplay between health insurance and having a regular source of care on control of BP is complex. ${ }^{31}$ Previous work in our hospital, an inner-city setting, has shown lack of insurance as the variable most associated with not having a regular source of care. ${ }^{44}$ For indigent patients terminated from a state Medicaid program, BP control considerably worsened, and only half of the terminated patients had a regular source of care. ${ }^{21}$ Blood pressure control improved for a comparison group of hypertensive patients who remained in the Medicaid program. In a veterans hospital population, hypertensive patients involuntarily discharged from routine outpatient care had a worsening in their BP when compared with baseline. ${ }^{22}$ Those who reported a financial barrier to receiving care had a significantly greater rise in $\mathrm{BP}$ than those who cited no such barrier. Data from the 1982 NHIS and the 1987 National Medical Expenditure Survey support the concept that receiving care for hypertension was more strongly associated with having a regular source of care than with insurance status. ${ }^{24,25}$

Our second finding was that educational level and knowledge about hypertension were not associated with controlled hypertension. Knowledge levels were quite high; patients knew if their most recent $\mathrm{BP}$ reading was high, low, or normal at levels exceeding the goals of the Healthy People 2000 effort. ${ }^{15}$ In the Hypertension FollowUp and Detection Program conducted in the 1980s, edu-

Table 2. Adjusted Odds Ratio for Controlled Blood Pressure Among Case and Control Patients in a Logistic Regression Model

\begin{tabular}{lrr}
\hline \hline & \multicolumn{2}{c}{ Odds Ratio (95\% Cl) } \\
\cline { 2 - 3 } \multicolumn{1}{c}{ Factors Associated with Controlled Blood Pressure* } & Without Cost & With Cost \\
\hline Having a regular source of care & $7.70(3.81,15.56)$ & $7.93(3.86,16.29)$ \\
Having been to a doctor in the last 6 months & $4.64(1.16,18.62)$ & $4.81(1.14,20.31)$ \\
Cost not a deterrent in buying antihypertensive medication & - & $3.63(1.59,8.28)$ \\
Presence of any medical insurance & $2.46(1.20,5.04)$ & $2.15(1.02,4.52)$ \\
Compliance with antihypertensive medication regimen & $2.04(1.05,3.99)$ & $1.96(0.99,3.88)$ \\
\hline
\end{tabular}

*Adjusting for age, gender, race, education, owning a telephone, and family income. 
cational level was inversely correlated with increasing severity of hypertension. ${ }^{45}$ It is possible that health education initiatives, such as the National High Blood Pressure Education Program, ${ }^{46}$ have reached inner-city minority populations and have been effective. Nonetheless, knowledge of one's diagnosis and antihypertensive medications does not appear sufficient for BP control.

A physician visit in the last 6 months was strongly associated with controlled BP. This finding should not be surprising as the most powerful variable leading to controlled BP is the actual intake of an antihypertensive medication. At our site, refills from continuity clinics are good for up to 6 months, and refills from sites such as the emergency department or walk-in clinic are good for 2 months. Therefore, at our setting, a physician visit in the last 6 months would be a requirement for an adequate supply of medications to last for 6 months. One study found that patients not seeing a physician in the previous year were three times more likely to have a DBP above $100 \mathrm{~mm} \mathrm{Hg.}{ }^{47}$ Data from the NHIS (1990) also support a strong association between having seen a physician within the preceding year and taking action to control BP. ${ }^{48}$

We found that patients self-reported that costs were a deterrent in both buying antihypertensive medications and seeing a physician, and that these were correlated with uncontrolled BP. The RAND study also found that free care improved DBP readings in low-income patients with hypertension. ${ }^{23}$ Although patients rarely cite cost as a reason for failure to take medication or keep appointments, cost appears to be a more frequent barrier to effective therapy than is generally appreciated. ${ }^{13,49}$ In this study, the surprisingly few patients that cited costs of antihypertensive medications and physician care as a barrier may be unique to our facility and some other public hospitals. Our hospital has a liberal sliding scale policy such that approximately $40 \%$ of all patients have no copayment or no charge for medications and physician visits at the hospital. In a setting without a generous sliding scale policy, physicians may need to reconsider prescribing higher priced antihypertensive medications, when less expensive options may be of equal efficacy. ${ }^{50}$

Medication compliance, as measured by Morisky's four-question scale, was associated with BP control; although the significance did decrease after addition of the cost barrier variable. In the Hypertension Detection and Follow-Up Program, pill counts correlated directly with controlled BP. ${ }^{51}$ Previous work, using different self-reported measures for antihypertensive medication compliance, found that patients with controlled hypertension were $67 \%$ compliant, whereas $46 \%$ of those with elevated BP were compliant, ${ }^{41,52}$ similar to our findings of $67 \%$ and $47 \%$, respectively. Our findings are also similar to those in other work reporting that $60 \%$ of hypertensive patients take their medication as prescribed. ${ }^{53}$

In our study population, Medicaid is as effective as other forms of insurance in leading to controlled BP. This finding may be explained by the lack of copayments for physician visits and prescription medications. Previous work in a less indigent patient population found that Medicaid patients had less access to care than privately insured patients. ${ }^{29}$ Other studies have found that patients with Medicaid coverage have greater difficulty finding a regular source of care in the community. ${ }^{54}$ In Georgia, Medicaid recipients receive up to five approved prescription medications. Previous work has shown that Medicaid recipients are less likely than uninsured lowincome patients to report difficulty affording prescription medication. ${ }^{49}$ The availability of antihypertensive medication at no cost to Medicaid recipients most likely plays a direct role in enabling control of hypertension. Patients in our study who had other forms of insurance were largely insured by Medicare. The basic Medicare plan (policy A) and Medicare supplement (policy B) provide no coverage for prescription drugs. Medigap supplemental policies rarely cover prescription drugs, and when they do, they generally require a $\$ 250$ annual deductible, 50\% copayment, and a monthly premium. ${ }^{49}$

Limitations of the study should be noted. First, much of the information was collected by self-report. Although patients may be confused about reporting a regular source of care ${ }^{55} \mathrm{we}$, and others, believe that patients' perceptions are an accurate reflection of this measure. Selfreport of antihypertensive medication use has been reported to be fairly accurate. ${ }^{56}$ Second, BP measurements were taken before the patient interview, which could lead to observation bias. However, the research assistant obtaining the measurements was blinded to the study hypothesis. Third, the generalizability of this study is limited to populations similar to the one studied, and our findings may not explain the rate of poor hypertension control in the U.S. population as a whole, more than $80 \%$ of whom have health insurance. ${ }^{57}$ Others have documented low rates of $\mathrm{BP}$ control even in a fully insured group of unionized health workers with ample access to primary care providers. ${ }^{58}$ Finally, other nonfinancial barriers to care exist in our population, including lack of transportation, exposure to violence, and living in a supervised setting. ${ }^{44}$

Our findings show that in an indigent population, having a regular source of care, having recently been to a doctor, costs not being a deterrent in purchasing antihypertensive medications, having health insurance, and being compliant with antihypertensive medication regimens are significantly associated with controlled hypertension. Improved access to continuity of care and increased physician sensitivity to medication costs, for both insured and uninsured patients, should improve BP control. Our findings also point to the importance of Medicaid coverage in indigent communities. It is likely that the absence of outof-pocket expenditures for medications and physician visits contributes in a significant way to BP control in this population. In addition, it appears that providing health insurance alone is not sufficient for hypertension control; ensuring access to a regular source of care may be even more important. Providing accessible primary care, educating 
patients about the importance of a regular source of care, and reducing barriers for patients to develop a relationship with a regular source of care should be high priorities.

The authors would like to express their sincere appreciation to Dr. Narendra Kanuru for his work as a research assistant in data collection, to Scott Clark, PhD, for statistical assistance, and to Ron Hall, MA, and Ms. Barbara Gibbs-Hodge for assistance with manuscript preparation.

\section{REFERENCES}

1. Joint National Committee on Detection, Evaluation, and Treatment of High Blood Pressure. The fifth report of the Joint National Committee on Detection, Evaluation, and Treatment of High Blood Pressure (JNC V). Arch Intern Med. 1993;153:154-83.

2. Rivo ML, Saultz JW, Wartman SA, DeWitt TG. Defining the generalist physician's training. JAMA. 1994;271:1499-504.

3. Calhoun DA, Oparil S. Hypertensive crisis since FDR-a partial victory. N Engl J Med. 1995;332:1029-30.

4. Whelton PK, Brancati FL. Hypertension management in populations. Clin Exp Hypertens. 1993;15:1147-56.

5. Bennett NM, Shea S. Hypertensive emergency: case criteria, sociodemographic profile, and previous care of 100 cases. Am J Public Health. 1988;78:636-40.

6. Materson BJ, Reda DJ, Cushman WC, et al. Single-drug therapy for hypertension in men-a comparison of six antihypertensive agents with placebo. N Engl J Med. 1993;328:914-21.

7. Burt VL, Whelton P, Roccella EJ, et al. Prevalence of hypertension in the US adult population. Hypertension. 1995;25:305-13.

8. Moorman PG, Hames CG, Tyroler HA. Socioeconomic status and morbidity and mortality in hypertensive blacks. In: Saunders E, ed. Cardiovascular Diseases in Blacks. Philadelphia, Pa: FA Davis Co; 1991:179-92.

9. Kaplan NM. Ethnic aspects of hypertension. Lancet. 1994;344:450-1.

10. Keeler EB, Brook RH, Goldberg GA, Kamberg CJ, Newhouse JP. How free care reduced hypertension in the health insurance experiment. JAMA. 1985;254:1926-31.

11. Saunders E. Tailoring treatment to minority patients. Am J Med. 1990;88(suppl 3B):21S-23S.

12. Haywood J. Hypertension in minority populations. Am J Med. 1990;88(suppl 3B): 17S-20S.

13. Shulman NB, Martinez B, Brogan D, Carr AA, Miles CG. Financial cost as an obstacle to hypertension therapy. Am J Public Health. 1986;76:1105-8.

14. Klag MJ, Whelton PK, Randall BL, et al. Blood pressure and endstage renal disease in men. N Engl J Med. 1996;334:13-8.

15. U.S. Dept. Health and Human Services. Healthy People 2000: National Health Promotion and Disease Prevention Objectives. Washington, DC: Government Printing Office; 1991.

16. Aday LA, Anderson R. A framework for the study of access to medical care. Health Serv Res. Fall 1974: 208-20.

17. Gonzalez-Fernandez RA, Rivera M, Torres D, Quiles J, Jackson A. Usefulness of a systemic hypertension in-hospital educational program. Am J Cardiol. 1990;65:1384-6.

18. Farquhar JW, Fortmann SP, Flora JA, et al. Effects of communitywide education on cardiovascular disease risk factors-the Stanford Five-City Project. JAMA. 1990;264:359-65.

19. Levine DM, Green LW, Deeds SG, Chwalow J, Russell RP, Finlay J. Health education for hypertensive patients. JAMA. 1979;241:1700-3.

20. Shea S, Misra D, Ehrlich MH, Field L, Francis CK. Predisposing factors for severe, uncontrolled hypertension in an inner-city minority population. N Engl J Med. 1992;327:776-81.

21. Lurie N, Ward NB, Shapiro MF, Brook RH. Termination from MediCal. Does it affect health? N Engl J Med. 1984;311:482-4.
22. Fihn SD, Wicher JB. Withdrawing routine outpatient medical services: effects on access and health. J Gen Intern Med. 1988;3:356-62.

23. Brook RH, Ware JE, Rogers WH, et al. Does free care improve adults health? Results from a randomized controlled trial. N Engl J Med. 1983;309:1426-34.

24. Woolhandler S, Himmelstein DU. Reverse targeting of preventive care due to lack of health insurance. JAMA. 1988;259:2872-4.

25. Moy E, Bartman BA, Weir MR. Access to hypertensive care: effects of income, insurance and source of care. Arch Intern Med. 1995; 155:1497-1502.

26. Haynes RB. Strategies to improve compliance with referrals, appointments, and prescribed medical regimens. In: Sackett DL, Haynes RB, eds. Compliance in Health Care. Baltimore, Md: The Johns Hopkins University Press; 1979:121-43.

27. Reif MC, Carter VL. The retail cost of antihypertensive therapyphysician and patient as educated consumers. Am J Hypertens. 1994;7:571-5.

28. Stason WB. Cost and quality trade-offs in the treatment of hypertension. Hypertension. 1989;13(suppl I):I -145-8.

29. Braveman P, Schaaf VM, Egerter S, Bennett T, Schecter W. Insurance-related differences in the risk of ruptured appendix. N Engl J Med. 1994;331:444-9.

30. Baker DW, Stevens CD, Brook RH. Regular source of ambulatory care and medical care utilization by patients presenting to a public hospital emergency department. JAMA. 1994;271:1909-12.

31. Kogan MD, Alexander GR, Teitelbaum MA, Jack BW, Kotelchuck M, Pappas G. The effect of gaps in health insurance on continuity of a regular source of care among preschool-aged children in the United States. JAMA. 1995;274:1429-35.

32. Stoddard JJ, St Peter RF, Newacheck PW. Health insurance status and ambulatory care for children. N Engl J Med. 1995;330:142 1-5.

33. Williams MV, Parker RM, Baker DW, et al. Inadequate functional health literacy among patients at two public hospitals. JAMA. 1995;274:1677-82.

34. Burch GE, DePasquale NP. Primer of Clinical Measurement of Blood Pressure. St. Louis, Mo: CV Mosby Co; 1962.

35. Reeves RA. Does this patient have hypertension? JAMA. 1995; 273:1211-8.

36. Chyba MM, Washington LR. Vital and health statistics: questionnaires from the National Health Interview Survey, 1985-89. National Center for Health Statistics. Vital Health Stat. 1993;1(31).

37. Stewart AL, Hays RD, Ware JE Jr. The MOS short-form general health survey: reliability and validity in a patient population. Med Care. 1988;26:724-35.

38. Ewing JA. Detecting alcoholism: the CAGE questionnaire. JAMA. 1984;252:1905-7.

39. Buchsbaum DG, Buchanan RG, Centor RM, Schnoll SH, Lawton MJ. Screening for alcohol abuse using CAGE scores and likelihood ratios. Ann Intern Med. 1991;115:774-7.

40. Shea S, Misra D, Ehrlich MH, Field L, Francis CK. Correlates on nonadherence to hypertension treatment in an inner-city minority population. Am J Public Health. 1992;82:1607-11.

41. Morisky DE, Green LW, Levine DM. Concurrent and predictive validity of a self-reported measure of medication adherence. Med Care. 1986;24:67-74.

42. Dean AG, Dean JA, Burton AH, Dicker RC. Epi Info. 5.01b ed. Stone Mountain, Ga: USD, Inc.; 1990

43. SAS Institute Inc. SAS/STAT User's Guide. 6.0 ed. Cary, NC: SAS Institute Inc.; 1989.

44. Rask KJ, Williams MV, Parker RM, McNagny SE. Obstacles predicting lack of a regular provider and delays in seeking care for patients at an urban public hospital. JAMA. 1994;271:1931-3.

45. Daughtery SA. Hypertension Detection and Follow-up Program Cooperative Group. Description of enumerated and screened population. Hypertension. 1983;5(suppl IV):1-43.

46. Rocella EJ, Horan MJ. The National High Blood Pressure Education Program: measuring progress and assessing its impact. Health Psychol. 1988;7:297-303. 
47. Wagner EH, Warner JT, Slome C. Medical care use and hypertension. Med Care. 1980;18:1241-50.

48. Centers for Disease Control. Adults taking action to control their blood pressure-United States, 1990. MMWR. 1994;43:509-11.

49. Strickland WJ, Hanson CM. Coping with the cost of prescription drugs. J Health Care Poor Underserved. 1996;7:50-63.

50. Manolio TA, Cutler JA, Furberg CD, Psaty BM, Whelton PK, Applegate WB. Trends in pharmacologic management of hypertension in the United States. Arch Intern Med. 1995;155:829-37.

51. Shulman N, Cutter G, Daugherty R, et al. Correlates of attendance and compliance in the hypertension detection and follow-up program. Control Clin Trials. 1982;3:13-27.

52. Haynes RB, Taylor DW, Sackett DL, Gibson ES, Bernholz CD, Mukherjee J. Can simple clinical measurements detect patient noncompliance? Hypertension. 1980;2:757-64.
53. Klein KE. Compliance and blood pressure control. Hypertension. 1988; 11 (suppl II):II/61-4.

54. The Medicaid Access Study Group. Access of Medicaid recipients to outpatient care. N Engl J Med. 1994;330:1426-30.

55. Perloff JD, Morris NM. Asking about the usual source of care-an appraisal of health care survey alternatives. Med Care. 1992; 30:950-7.

56. Paganini-Hill A, Ross RK. Reliability of recall of drug usage and other health-related information. Am J Epidemiol. 1982;116:11422.

57. Monheit AC. Underinsured Americans: a review. Annu Rev Public Health. 1994;15:461-85.

58. Stockwell DH, Madhavan S, Cohen H, Gibson G, Alderman MH. The determinants of hypertension awareness, treatment, and control in an insured population. Am J Public Health. 1994;84:1768-74.

\section{JGIM's E-mail Address}

For Letters to the Editor or for information about submitting manuscripts to JGIM: Walklett@mail.med.upenn.edu 